\title{
Calcium and aluminium-based fillers as flame-retardant additives in silicone matrices II. Analyses on composite residues from an industrial-based pyrolysis test
}

\author{
Siska Hamdani-Devarennes ${ }^{\mathrm{a}}$, Audrey Pommier ${ }^{\mathrm{a}}$, Claire Longuet $^{\mathrm{a}}$, \\ José-Marie Lopez-Cuesta ${ }^{\mathrm{a}, * *}$, François Ganachaud ${ }^{\mathrm{b}, *}$ \\ ${ }^{a}$ Centre des Matériaux de Grande Diffusion, Ecole des Mines d'Alès, 6 avenue de Clavières, 30319 ALES Cedex, France \\ b Institut Charles Gerhardt UMR5253 CNRS/UM2/ENSCM/UM1, Equipe Ingénierie et Architectures Macromoléculaires, Ecole Nationale Supérieure de Chimie de Montpellier, \\ 8 Rue de l'Ecole Normale, 34296 Montpellier Cedex, France
}

\begin{abstract}
A B S T R A C T
The second part of this series, devoted to the study of model fire-resistant silicone composites filled with calcium or aluminium-based material which would meet cable industry specifications, focuses on residues obtained after extreme pyrolysis adapted from the NFC 32070 CR1 French standard. Several methods of analysis (among them ESEM, EDX, XRD, Hg pycnometer, and compression tests) have been carried out in order to investigate the microstructure, volume variation, and compression behaviour of silicone composite residues. Calcium-based fillers produced more cohesive residues than aluminiumbased fillers. Indeed, the co-crystallisation taking place during pyrolysis, as shown in the first part of this series (Hamdani, S. et al., Polym Degrad Stab, 2010, 95, 1911-1919), produced a dense and strong residue. The strong internal porosity and absence of new crystal formation in residues of aluminiumbased filled composites resulted in their low compressive resistance. In addition, water release during the degradation of the latter fillers, favoured residue expansion, high interior porosity and thus weak compression resistance.
\end{abstract}

Keywords:

Silicone

Fillers

Calcium

Aluminum

Pyrolysis

Residue

\section{Introduction}

The demand for electric cables able to operate during a fire and limit fire propagation is constantly increasing. Government regulations in various countries now specify that essential electrical circuits be protected in order to ensure the safety of persons inside the building and also to permit the firemen to be more efficient in controlling and extinguishing fires. Such systems include, for example, alarms, telephones, lighting, elevators, ventilation, fire pumps, and so on. Therefore, depending on the country of application, national standard tests of different difficulties have to be passed before launching electrical cables with improved fire resistant coatings. In France particularly, the NFC 32070 CR1 standard test imposes that cables sustain electrical power after burning at a high heating rate (above $80^{\circ} \mathrm{C} / \mathrm{min}$ ) in inert atmosphere while being periodically mechanically shocked during the test. The

\footnotetext{
* Corresponding author. Tel.: +33 4671472 96; fax: +33 467147220 .

** Corresponding author. Tel.: +33 4667853 34; fax: +33 466785365 .

E-mail addresses: jose-marie.lopez-cuesta@mines-ales.fr (J.-M. Lopez-Cuesta),
}

temperature is finally maintained at $900{ }^{\circ} \mathrm{C}$ for $15 \mathrm{~min}$. The test is passed if the cables retain electrical insulation under thermal and mechanical stresses [1]. In England, the national standard test of BS EN 50200:2006, based on European standard EN 50200, implies a direct application to the cable of a flame from a propane burner, giving a constant temperature attack of a notional $842{ }^{\circ} \mathrm{C}$. This method allows testing cables used in emergency circuits [2]. In Australia, the fire test condition for cables, known as Australian Standard AS/NZS3013:1995, requires that the cable be fired in air up to $1050^{\circ} \mathrm{C}$ and maintained at a maximum firing temperature for $30 \mathrm{~min}$, then sprayed with a water jet. The test is valid if the residue resists the small mechanical shocks from the water spray.

To fulfil these requirements and avoid e.g. short circuits during the fire, a silicone coating producing a cohesive residue after burning is particularly sought. From this prospective, different studies have been carried out to understand the cohesion residue mechanism in polymers and several methods have also been proposed to obtain a strong char, for example by incorporation of nanofillers into composites [3,4]. Nevertheless, to our knowledge there is still only a limited number of papers that reported the characterisation of cohesion residue of composites, in particular for 
silicone composites. Mansouri et al. [5] characterised the residue of silicone composite by flexural strength measurement on pyrolysed samples, using the three-point bend method. This method measured the mechanical properties of a bulk residue, while in our case, we are also interested in measuring the influence of surface layering on the residue cohesion. Laoutid et al. [3] used a microindentation test to evaluate the mechanical behaviour of EVA combustion residue. The material was submitted to a plastic deformation by penetration of an indenter forced into the material under a load and recorded as a function of the depth of the indentation. Unfortunately, this method requires a residue with two parallel faces, which is not the case for our residues.

Since the NFC 32070 CR1 standard test specifications are hardly passed by most current high-tech silicone formulations, it requires further fundamental research to understand the role of each potential fire-resistant additive. The present series of papers thus aims at considering the role of calcium and aluminium-based inorganic fillers as additives for a new generation of fire-resistant cables. In the first part of this series [6], we described the characteristics of a variety of fillers chosen for this work, their blending in a model silicone matrix and the thermogravimetric analyses of resulting composites. From these, we classified silicones composites into three groups regarding their thermal behaviour, whether they contain inert fillers, water-releasing fillers, or hydroxylfunctionalized fillers. Non-hydrated fillers improved the thermogravimetric stability of silicone, while water-releasing and/or hydroxyl-decorated fillers depressed it.

The current study focuses primarily on the content and cohesion of the residue arising from a simulation of an extreme fire test such as NFC 32070 CR1 standard test, but without exerting mechanical shocks during burning. Samples were fired in stainless steel tubes, a confinement corresponding roughly to working in inert atmosphere. The high heating rate imposed here is believed to mimic conditions from a real fire case. In this paper, complementary understandings about the role of each kind of filler, introduced in the silicone cable formulation, on the cohesion residue (compared to thermal stability, as reported in the first part of this series [6]) are given. The third part will describe the fire behaviour of similar silicone composites in fire tests using complementary calorimeter techniques.

\section{Experimental part}

\subsection{Materials}

The silicone matrix, kindly supplied by Bluestar Silicones, contains $74.4 \mathrm{wt} . \%$ of vinyl-terminated polydimethylsiloxane $\left(M_{\mathrm{W}}\right.$ of $550,000 \mathrm{~g} / \mathrm{mol}$ ), $25 \mathrm{wt} . \%$ of $\mathrm{D}_{4}$-modified silica and $0.6 \mathrm{wt} . \%$ of 2.5-dimethyl-2.5-di(tert-butyl peroxy)hexane as a crosslinking agent. Precipitated calcium carbonate (PCC), wollastonite, and boehmite were supplied by Solvay, Nyco minerals and Nabaltec respectively. ATH was purchased from Martinswerk, alumina from Evonik and mica from Kaolin International. For a complete and thorough characterisation of all fillers, see the supporting information (Table S1).

\subsection{Sample preparation}

Fillers were incorporated into the silicone matrix using a HAAKE internal mixer at a temperature of $45^{\circ} \mathrm{C}$, shear rate of $40 \mathrm{rpm}$ and mixing time of $50 \mathrm{~min}$. The HAAKE internal mixer has two rotors running in a contra-rotating way to blend the filler and the matrix. All composites contained $20 \mathrm{wt} \%$ of silica and $20 \mathrm{wt} \%$ of filler. Thereafter, filled silicone was cross-linked under heat pressure of 90 bars at $150^{\circ} \mathrm{C}$ during $15 \mathrm{~min}$ to obtain plates of $100 \times 100 \times 3.8 \mathrm{~mm}$. The effectiveness of mixture dispersion was confirmed by ESEM analysis as reported previously [6].

\subsection{Sample pyrolysis}

Samples with dimension of $20 \times 15 \times 3.8 \mathrm{~mm}$ or $10 \times 10 \times 3.8 \mathrm{~mm}$, depending on applied tests, were confined in a paired system of stainless steel tubes $\left(\varnothing_{1}=30 \mathrm{~mm}\right.$, and $\emptyset_{2}=35 \mathrm{~mm}$ ) to limit thermo-oxidation by oxygen in air and ash contamination of the furnace (Fig. 1). In order to simulate real fire conditions, the thermal ramp was adapted from CR1 NFC 32070 standard test. Typically, samples were burned in a Nabertherm furnace from $40^{\circ} \mathrm{C}$ to $940^{\circ} \mathrm{C}$ in a 40 min time lag followed by an isotherm at $940^{\circ} \mathrm{C}$ during $15 \mathrm{~min}$.

\subsection{Characterisation of residues}

A Hitachi S-4300 environmental scanning electron microscope (ESEM) was used to acquire analyses on the microstructure of silicone composite residues under a magnification of $5000 \times$ using an acceleration voltage of $15 \mathrm{kV}$. Energy-dispersive X-Ray (EDX) measurements were conducted as an integrated tool in ESEM to determine local elemental composition on micrographs with a magnitude of $300 \times$. The averaged element contents were measured from three observation points, on the surface and on the fractured side of the residues, during ESEM analysis.

Table 1

Structure behaviour, volume variation, XRD, and EDX elemental analysis of residues.

\begin{tabular}{|c|c|c|c|c|c|c|c|c|}
\hline \multirow[t]{3}{*}{ Filler } & \multicolumn{2}{|l|}{ Microstructure } & \multirow{3}{*}{$\begin{array}{l}\text { Volume } \\
\text { variation (\%) }\end{array}$} & \multirow{3}{*}{$\begin{array}{l}\text { Co-crystallisation } \\
\text { observed by XRD } \\
\text { analysis }\end{array}$} & \multicolumn{4}{|c|}{ Ca or Al relative to Si element content (\%) } \\
\hline & \multirow[t]{2}{*}{ Inside } & \multirow[t]{2}{*}{ Outside } & & & \multicolumn{2}{|l|}{ Composite } & \multicolumn{2}{|l|}{ Residue } \\
\hline & & & & & Surface & Interior & Surface & Interior \\
\hline PCC & Dense with low porosity & Rough with ceramic layer & $-52.4 \pm 2.9$ & $\begin{array}{l}\text { Wollastonite, } \\
\text { Calcium silicate }\end{array}$ & $20.4 \pm 0.9$ & $18.9 \pm 0.7$ & $63.3 \pm 0.7$ & $67.3 \pm 0.3$ \\
\hline Calcite & Dense with low porosity & Rough with ceramic layer & $-47.9 \pm 0.2$ & $\begin{array}{l}\text { Wollastonite, } \\
\text { Calcium silicate }\end{array}$ & $15.0 \pm 0.2$ & $15.5 \pm 0.6$ & $38.7 \pm 0.7$ & $40.6 \pm 0.2$ \\
\hline Wollastonite & $\begin{array}{l}\text { Smooth and fillers found } \\
\text { everywhere }\end{array}$ & Filler not bound to matrix & $-7.0 \pm 5.3$ & Wollastonite & $4.5 \pm 2.5$ & $12.0 \pm 0.4$ & $26.9 \pm 0.3$ & $24.9 \pm 2.0$ \\
\hline $\begin{array}{l}\text { Calcium } \\
\text { hydroxide }\end{array}$ & $\begin{array}{l}\text { Dense with low porosity } \\
\text { (crater like) and cottony }\end{array}$ & $\begin{array}{l}\text { Rough with ceramic layer } \\
\text { but slightly cottony }\end{array}$ & $10.2 \pm 2.3$ & $\begin{array}{l}\text { Wollastonite, } \\
\text { Calcium silicate, } \\
\text { Larnite }\end{array}$ & $0.7 \pm 0.2$ & $15.9 \pm 0.7$ & $47.3 \pm 0.5$ & $50.3 \pm 0.3$ \\
\hline ATH & High porosity (crater like) & Rough & $59.5 \pm 9.3$ & None & $15.7 \pm 0.1$ & $15.7 \pm 0.4$ & $37.1 \pm 1.3$ & $38.5 \pm 0.4$ \\
\hline Boehmite & Low porosity and cottony & Smooth & $24.7 \pm 4.3$ & None & $15.6 \pm 0.9$ & $15.9 \pm 0.3$ & $41.9 \pm 0.5$ & $41.8 \pm 0.3$ \\
\hline Alumina & Smooth and cottony & Smooth & $57.7 \pm 2.4$ & None & $20.3 \pm 1.0$ & $21.3 \pm 1.4$ & $34.7 \pm 0.5$ & $31.2 \pm 0.3$ \\
\hline Mica & $\begin{array}{l}\text { Porous and big void } \\
\text { among mica particles }\end{array}$ & Fillers well bound to matrix & $18.1 \pm 0.1$ & Muscovite & $4.8 \pm 0.3$ & $5.2 \pm 0.2$ & $19.0 \pm 1.4$ & $13.9 \pm 0.2$ \\
\hline
\end{tabular}




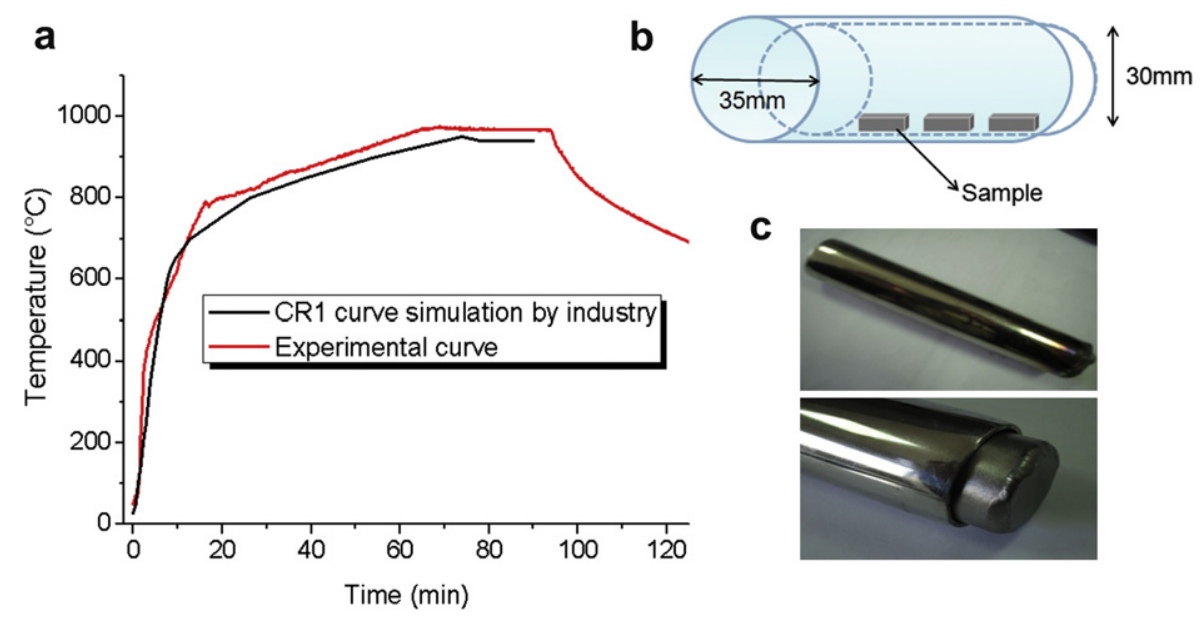

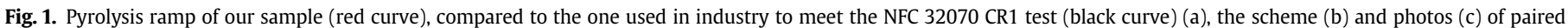
tubes used during pyrolysis (For interpretation of the references to color in this figure legend, the reader is referred to the web version of this article.).

X-Ray Diffraction (XRD) analyses of finely ground filler and final residues were performed on a Bruker X-ray diffractometer using $\mathrm{Cu}$ $\mathrm{K} \alpha$ radiation.

Volume variations before and after pyrolysis were measured by the mercury immersion method using Archimedes principle. An unfired sample (composite) with dimension of $20 \times 15 \times 4 \mathrm{~mm}$ was placed into a beaker glass filled with $\mathrm{Hg}$. The displaced $\mathrm{Hg}$ was weighed to define the initial volume of the sample (volume of composite) by taking $\mathrm{Hg}$ density as $13.6 \mathrm{~g} / \mathrm{cm}^{3}$. After pyrolysis, the volume of residue was measured similarly to the non-pyrolysed sample in $\mathrm{Hg}$. The volume variation is calculated by using Equations (1) and (2) as follows:

$\begin{aligned} \text { Volume variation }(\%)= & \frac{(\text { Volume })_{\text {residue }}-(\text { Volume })_{\text {composite }}}{(\text { Volume })_{\text {composite }}} \\ & \times 100 \%\end{aligned}$

in which the volume of residue or composite is calculated by

Volume $\left(\mathrm{cm}^{3}\right)=\frac{\text { Weight of the displaced } \mathrm{Hg}(\mathrm{g})}{13.6\left(\mathrm{~g} \mathrm{~cm}^{-3}\right)}$

The breaking resistance of the residue was measured using a compression tool (Fig. S1), connected to a 10 daN Zwick detector in an ADAMEL mechanical testing machine. Typically, burned samples were pressed by a cylindrical sensor with diameter $4 \mathrm{~mm}$ (initial sample dimension $100 \times 100 \times 4 \mathrm{~mm}$ ) at compression rate of $1 \mathrm{~mm} / \mathrm{min}$ under which the applied force $(\mathrm{N})$ and the compression depth $(\mathrm{mm})$ to break down the material were recorded. The results were reprocessed to determine the energy required to attain the maximum force, and the slope up to the first crack under the test (Fig. 2). The area under the peak of maximum force was considered as the energy required to destroy the material (when the force curve reaches a plateau, synonymous with powder compression, or shuts down, for a material that breaks into pieces, vide infra). The slope was taken as an indicator of the surface stiffness. The test was applied to at least 10 samples, because of the poor repeatability of the technique, from which most representative curves were taken and averaged.

\section{Results}

As stated in the introduction, composite samples were burned in a furnace under extreme pyrolysis conditions, according to NFC
32070 CR1 specifications. Silicone test materials were confined in paired stainless steel tubes with limited air content. Pyrolysis ranged from $40{ }^{\circ} \mathrm{C}$ to $940{ }^{\circ} \mathrm{C}$ over $40 \mathrm{~min}$, followed by an isotherm at $940{ }^{\circ} \mathrm{C}$ during $15 \mathrm{~min}$. Residues were then characterised by examining their inner and outer microstructures (by ESEM and optical microscopy), by determining their chemical transformation (by EDX elemental analysis and XRD analysis) and by estimating their cohesion (by volume variation and compressive resistance tests).

The structure of the matrix residue (no filler apart from $25 \mathrm{wt} \%$ silica) was first observed by ESEM and optical microscopy, as shown in Fig. S2. These blank analyses are necessary as a reference point compared to filled sample residue. Microstructures of matrix residue were relatively smooth and had few cracks, but some agglomerates of silica particles were found on the surface (Fig. S2). The cracks on the surface residue were principally attributed to the release of volatile products during silicone degradation.

\subsection{Structure of surface residues by optical microscopy}

The general appearance of residues of silicone composites after pyrolysis in extreme condition is presented in Fig. 3. Macroscopic

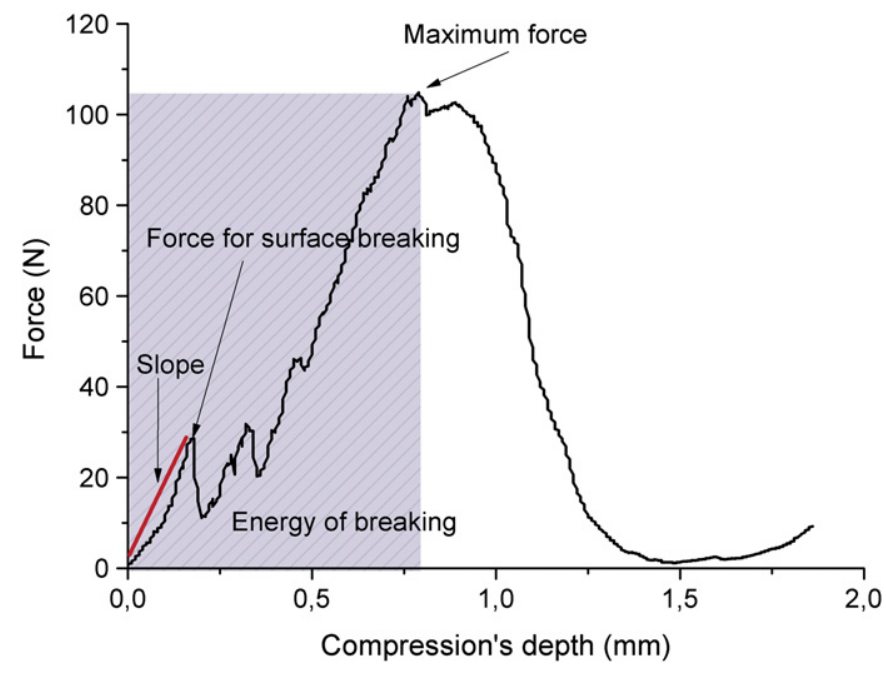

Fig. 2. Data observations from the compression test of residue PCC composite. 

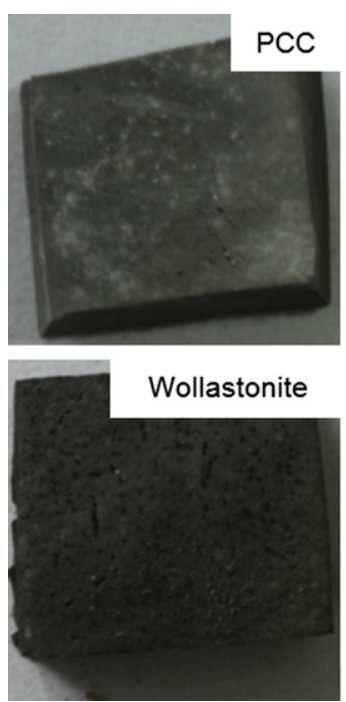
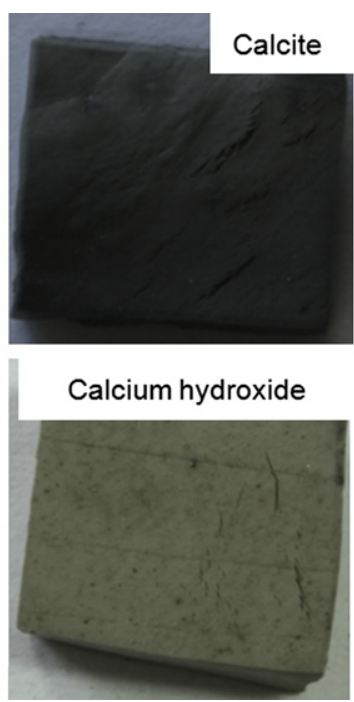
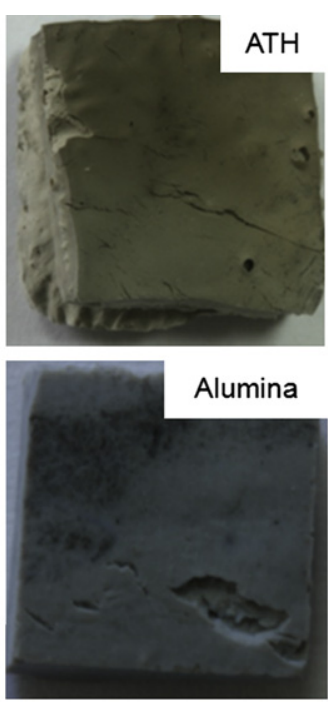
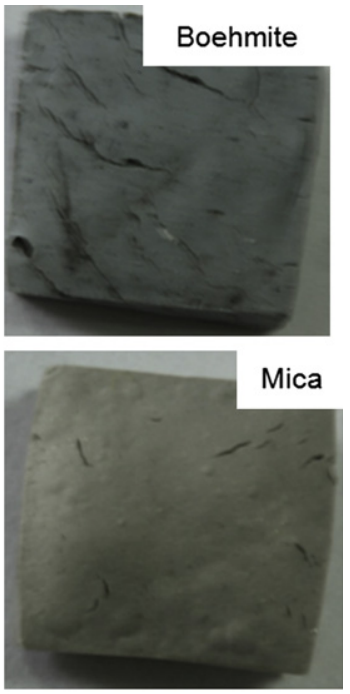

Fig. 3. Photographs of the surface morphologies of the residues (composites containing calcium- (left) or aluminium- (right) based fillers).

observation by optical microscopy was also systematically done on the microstructure of surface residues (Fig. 4).

Silicone composites containing nano-sized calcium carbonate (PCC), micro-sized calcium carbonate (calcite) or wollastonite produced residues with a very small amount of cracks on the surface. The residue of calcite composites exhibited slightly more cracks on the surface compared to PCC or wollastonite. In addition, silicone composites containing calcium hydroxide presented more cracks on the surface, probably because of water release from filler degradation.

All aluminium-based fillers presented cracks on their surfaces. High water release through thermal decomposition of ATH led to formation of numerous cracks everywhere on the surface, bigger than those from calcium hydroxide or boehmite composites. Residue of silicone composites containing mica and alumina also presented numerous cracks covering the surface. Volatiles released during the combustion may be water, $\mathrm{CO}_{2}$, or cyclic siloxanes, all of which entail crack formation in the composites during the test. Lower crack formation on calcium carbonates and wollastonite comes from the fact that volatiles released displayed no interactions with silicone during degradation at low temperature [6].

\subsection{ESEM analyses}

From ESEM images under magnification of $5000 \times$, a continuous ceramic layer was observed on the surface of PCC and calcite composite residues (Fig. 5). The surface residue of wollastonite composite presented some big filler particles slightly attached to the amorphous structure of matrix residue through a ceramic layer. The surface of calcium hydroxide composite was rough and cottony due to matrix degradation by water molecules released from the filler, and traces of cracks were also observed on the surface residue. Thanks to EDX analyses, we have identified that the cottony materials contains silicon atoms. Silica, either silica filler or silica from silicone degradation (mainly fumed silica) tends to accumulate near the surface without sinking through the polymer melt layer during the burning process [7].

In Fig. 6, no obvious porosities were observed on the surface of ATH and boehmite composites, probably because they degraded at rather low temperature (below $500{ }^{\circ} \mathrm{C}$ ). It is supposed that structural rearrangement of the residual network could occur while burning the composite up to $940^{\circ} \mathrm{C}$. ATH presented rough surface with some cottony agglomerates and traces of cracks, while boehmite showed, on the micrometer scale, a smoother surface.
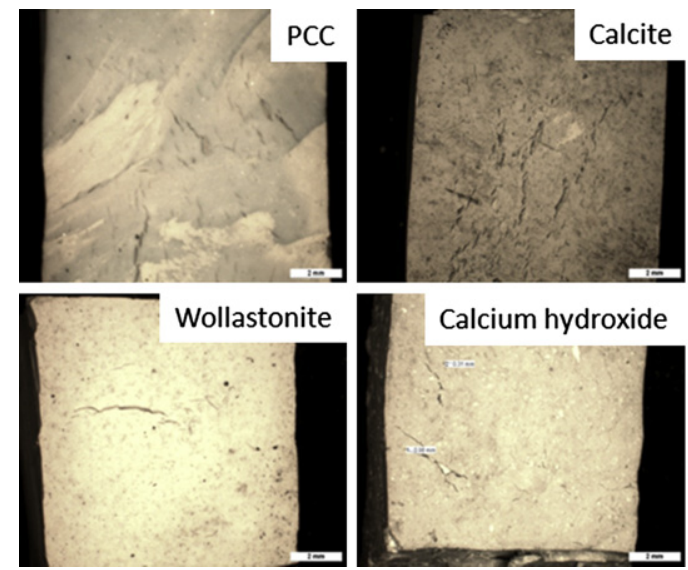
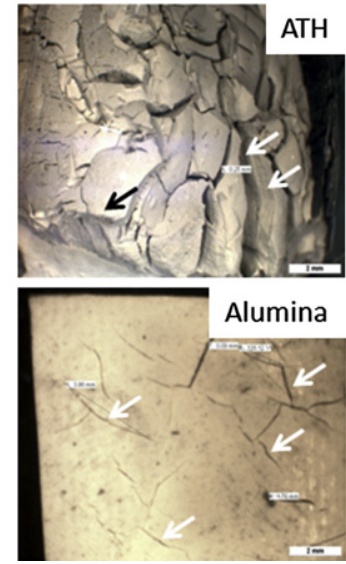
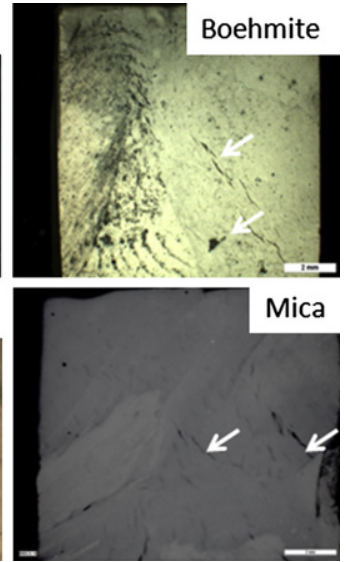

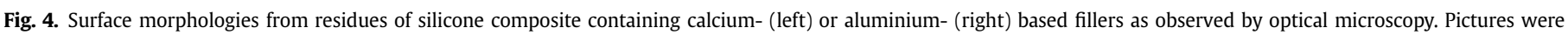
taken from the top of the samples with a magnification of $25 \times$. 

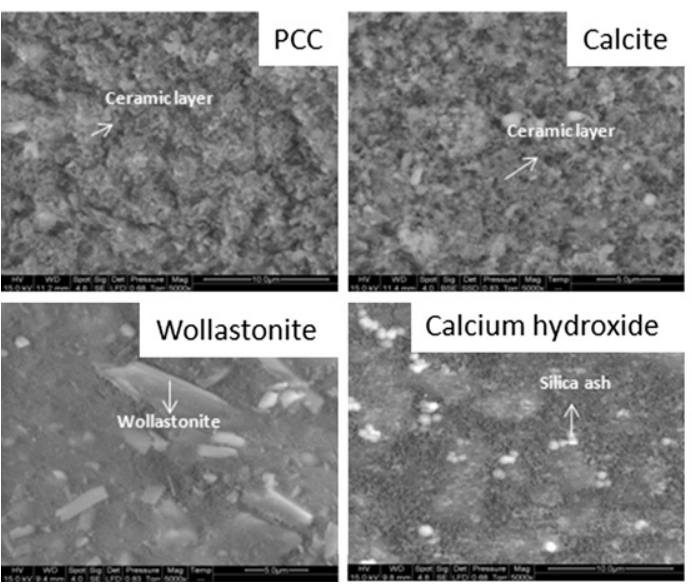
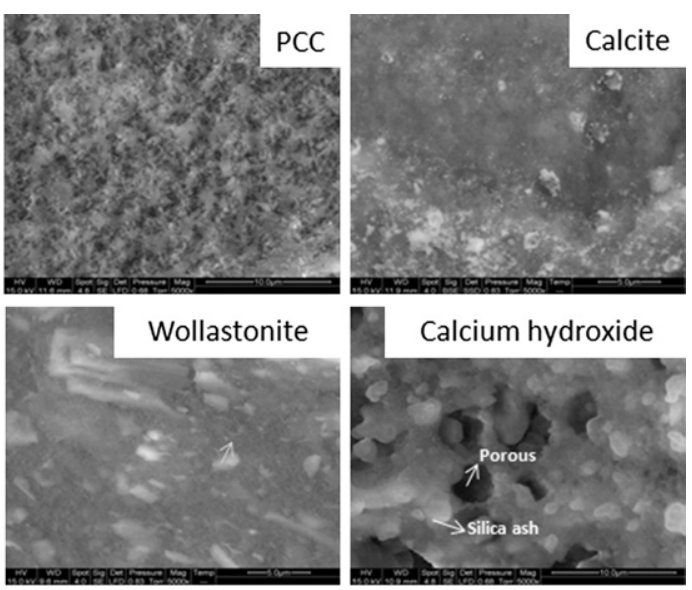

Fig. 5. ESEM images on surface (left) and interior (right) microstructures of pyrolysis residues from silicone composites containing calcium-based fillers.

Alumina composite also exhibited smooth surface residues. The sample containing mica presents surface residue with some individual mica particles found on the surface, apparently with a better cohesion to matrix residue than wollastonite particles.

The internal residue of composites containing calcium carbonates presented a minor porosity (Fig. 5), probably due to $\mathrm{CO}_{2}$ gas release during pyrolysis, with few ceramic continuous layers. While the internal residue of composites containing wollastonite presented no porosity, some isolated particles of wollastonite filler were found as well as cotton-like materials. Inside calcium hydroxide's residue, the crater-like surface was surrounded by ceramic materials. The big holes formation could be explained by matrix degradation due to strong water release from filler decomposition. It is suggested that these water molecules catalyse the degradation of the neighbouring silicone chains to release volatile and to leave holes behind them.

All aluminium-based fillers presented almost similar microstructure in their core, in which crater-like holes are surrounded by cottony materials (Fig. 6). However, ATH residue seemed to have bigger pores than other fillers, probably due to the larger water release from ATH degradation. Smaller fillers such as boehmite and alumina presented low porosity and cottony internal structure. A porous structure and big voids were observed among mica particles inside the residue of mica-based composite. Note that an observation by ESEM at high magnification, of the interior residues of mica and wollastonite composites showed the presence of microbridges in both cases (Fig. 7).

\subsection{XRD analysis}

XRD analysis of bulk residues confirmed the results previously reported in the first paper of this series devoted to thermogravimetric analyses [6]. The diffractograms of PCC, calcite, and calcium hydroxide residues are presented in Fig. S3. Ceramic-like materials in PCC and calcite residues were found to be composed of wollastonite and calcium silicate; two different $\mathrm{CaSiO}_{3}$ crystalline forms arose from in-situ crystallisation between $\mathrm{CaO}$ in filler and $\mathrm{SiO}_{2}$ in matrix. The XRD analysis of wollastonite confirmed the presence of filler in the residue, since wollastonite was stable during pyrolysis at $940{ }^{\circ} \mathrm{C}$. $\mathrm{CaO}$ from calcium hydroxide degradation product also reacted with silica to form wollastonite, calcium silicate, and larnite $\left(\mathrm{Ca}_{2} \mathrm{SiO}_{4}\right)$. The lower decomposition temperature of calcium hydroxide made the $\mathrm{CaO}$ available earlier and in higher content than calcium carbonate's composites to crystallise with silica. ATH, boehmite, and alumina residues did not lead to new crystallisation steps at high temperature. All of them degraded to form amorphous $\mathrm{Al}_{2} \mathrm{O}_{3}$, not visible on XRD. As for wollastonite, mica particles maintained their crystallinity after pyrolysis.

\subsection{Elemental analyses by EDX}

EDX analyses from ESEM images were carried out to obtain averaged elemental contents. Fig. 8 presents the $\mathrm{Ca}$ or $\mathrm{Al}$ element content (relative to Si element content) inside and at the surface of
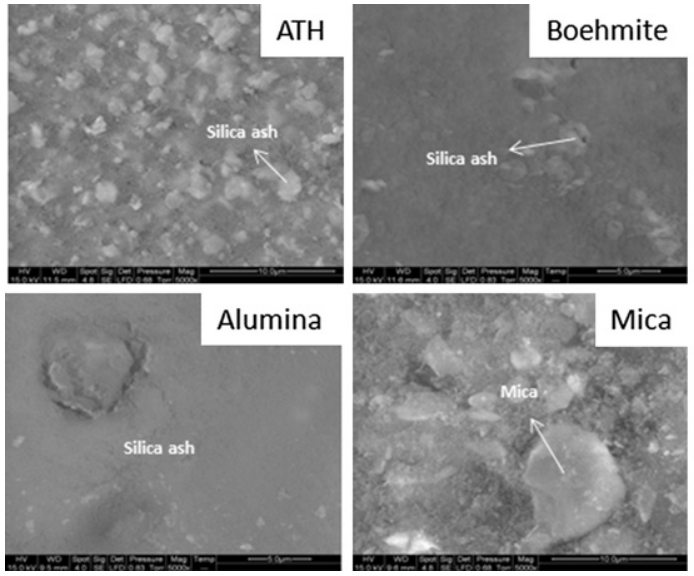
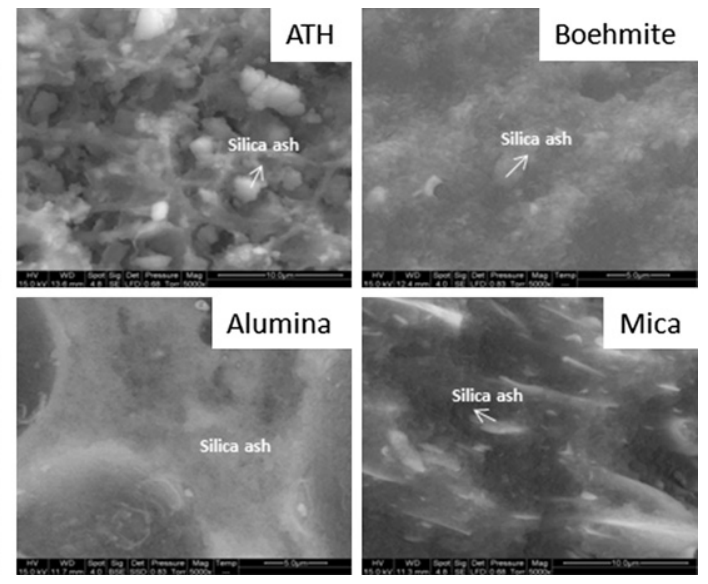

Fig. 6. ESEM images on surface (left) and interior (right) microstructure of pyrolysis residues from silicone composites containing aluminium-based fillers. 

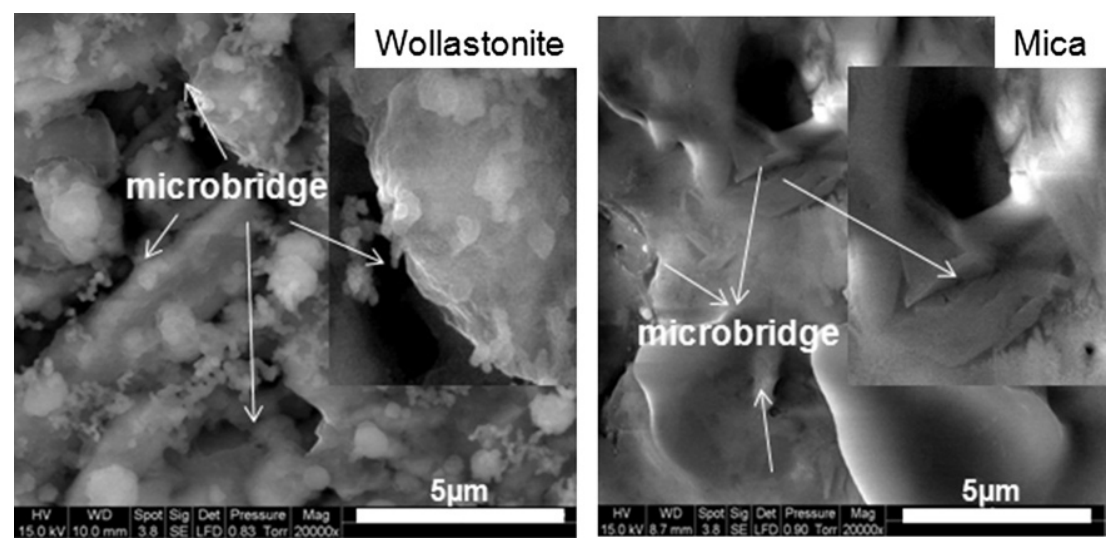

Fig. 7. Interior microstructures of pyrolysis residues from silicone composites containing wollastonite and mica under magnification of $20,000 \times$.

composites and residues. Note that increased Ca or $\mathrm{Al}$ content can also be interpreted as lower Si content.

In composites containing aluminium-based filler, ATH and boehmite residues showed almost homogeneous Al element distribution in the core (interior) and surface (exterior) of composites (Fig. 8a), but a slight difference was observed in alumina and mica composites. After pyrolysis, an increase of $\mathrm{Al}$ element content on the surface of mica and alumina residues were observed (Fig. 8b). Residue of mica has a richer Al content on the surface than alumina residue, which suggests either filler migration to surface, silica volatilisation or polymer ablation during pyrolysis.

Conversely, compositions of residues and composites of calcium-based fillers did not show such regular tendency. PCC and wollastonite composites presented slightly higher Ca content on its surface than in the interior, contrary to calcite, although differences are tenuous. Larger differences of Ca content on the surface and in the interior were found for the composites containing calcium hydroxide (Fig. 8a). After pyrolysis, all residues of calcium-based fillers except wollastonite have lower Ca content on surface than inside the residues, which may designate silica migration to surface (Fig. 8b), whereas higher Ca content on surface of wollastonite residue was presumably caused by polymer ablation, which left more wollastonite particles on the surface of the residue (see ESEM image Fig. 5).

\subsection{Volume variation analysis}

Volume variations were determined by the $\mathrm{Hg}$ displacement technique by comparing samples before and after pyrolysis. In this method done at atmospheric pressure, the internal porosity is ignored since $\mathrm{Hg}$ cannot penetrate into the internal closed pores (measuring the porosity of the samples would imply to use a mercury porosimeter working at high pressures that would break such brittle samples). Incorporation of aluminium or calcium-based fillers severely modified the volume variation of residues, as presented in Table 1 . The residues of PCC and calcite composites presented high residual shrinkage, 52\% and 48\% respectively. Incorporation of wollastonite had almost no influence on the

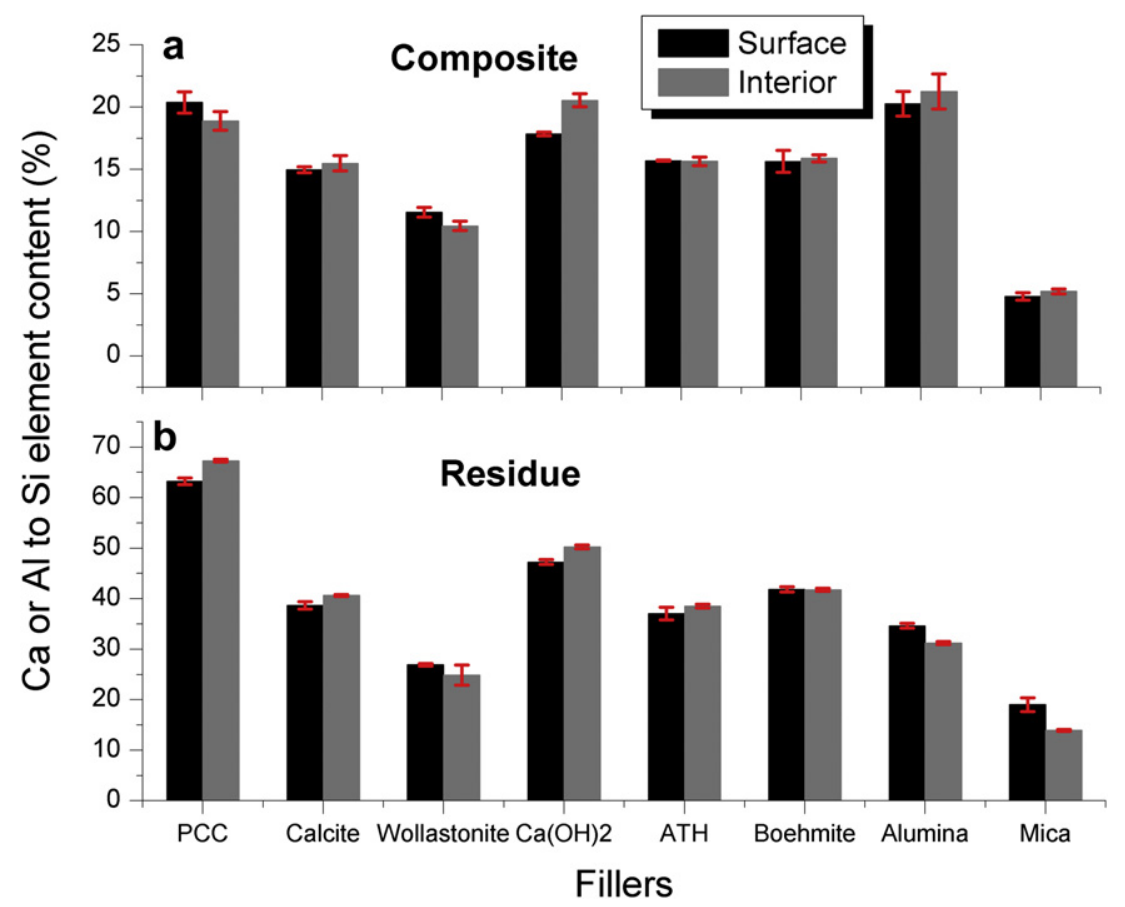

Fig. 8. Elemental analyses of $\mathrm{Al}$ or Ca contents (normalised by Si contents) inside (interior) and outside (surface) of composites and residues. 


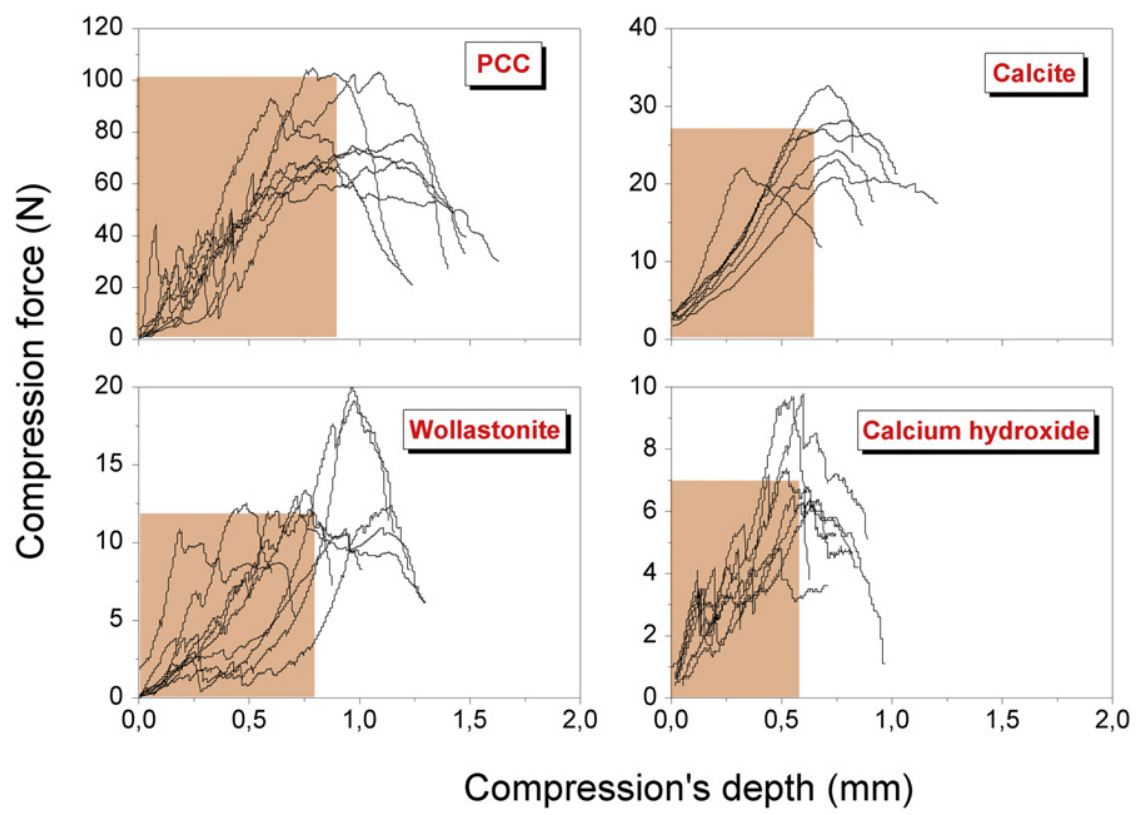

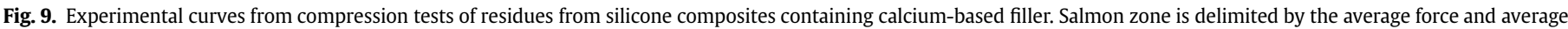
time to break down the residue, as calculated from all curves (see values in Table 2).

volume variation of composite's residue ( $7 \%$ shrinkage). Contrary to other calcium-based fillers, incorporation of calcium hydroxide resulted in $9 \%$ expansion volume of residue. All aluminium-based fillers presented significant volume expansions, large ones for ATH and alumina (60\% and 58\% respectively), while boehmite and mica exhibited lower volume expansion (25\% and $18 \%$ respectively).

\subsection{Compression tests}

Originally, micro-indentation measurements were planned to evaluate the mechanical strength of the residues [3]. Since most of these were brittle, we took advantage of this fragility to generate some "destruction curves" so as to discriminate between the different pyrolysed materials. Figs. 9 and 10 present the experimental curves from compression tests of calcium and aluminium based residues, respectively. As stated in the experimental part, the compression test was applied to at least 10 samples, because of the poor repeatability of the technique, especially for aluminium-based material residues. From all curves, we recorded the maximum force required to break down the bulk residue, noticed maximum compression force $(\mathrm{N})$, and the compression's depth at which this breaking occurs $(\mathrm{mm})$, including the area under the maximum force corresponding to energy required to break down residues

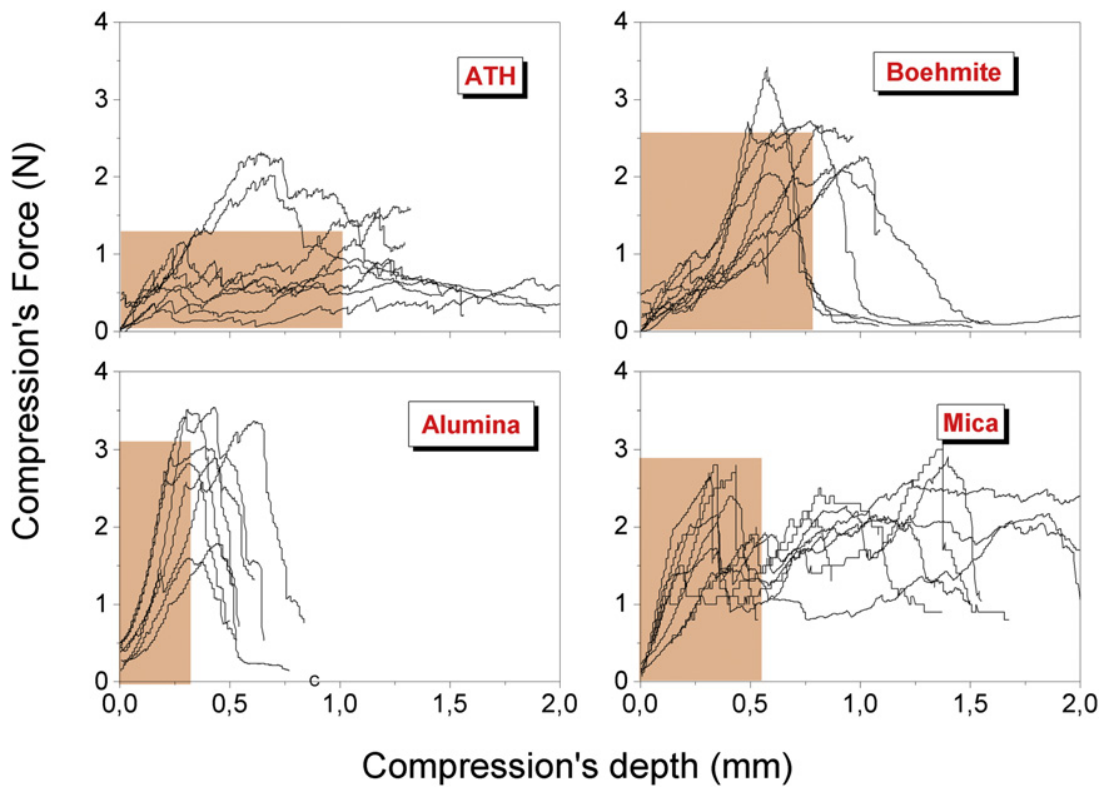

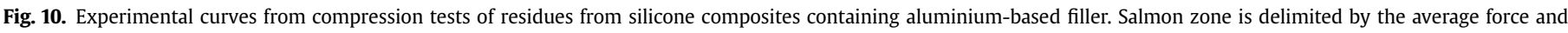
average time to break down the residue, as calculated from all curves (see values in Table 2). 


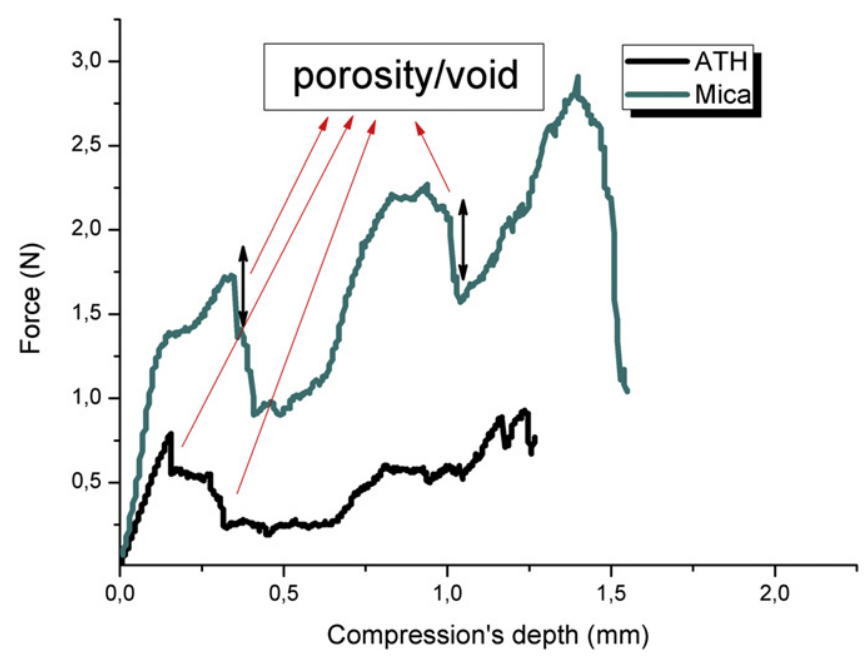

Fig. 11. Selected compression curves of residues of composites containing ATH and mica, showing the effect of the porosity on the compression measurements.

$(\mathrm{N} \mathrm{mm})$, and finally the slope up to the first peak under compression $(\mathrm{N} / \mathrm{mm}$ ) (see an example of data considered on the compression curve of PCC composite in Fig. 2). Note that the first peak that appears under test is assigned to a rupture of the surface layer. For porous residues, when the cylindrical sensor passes through a pore, the force goes down until the cylindrical sensor touches back the residue and then increases again, and this step is repeated until the maximum force is attained. For example, residues of mica and ATH composites which present some porosity, showed crenellated compression curves (Fig. 11).

All data were compiled, averaged and compared in Table 2 and Fig. 12. The residues containing aluminium-based fillers presented almost identical average values of maximum force of compression, energy, and penetration depth of cylindrical sensor (\%) to attain the maximum force of bulk residues. Even so, residue of mica composite required slightly higher force and energy to break down. The residue of alumina composite differed slightly, showing the lowest sensor penetration to break down; this residue gave highly powdered ashes compared to the others, in agreement with its brittleness and poor mechanical resistance.

More dissimilarity was observed for the residues of calciumbased composites. In general, they presented better compressive behaviours than ones of aluminium-based composites. PCC showed an outstanding compressive resistance of its residue compared to other tested calcium-based fillers; automatically it also required the highest sensor penetration (\%) to break down the residue of very dense structure. Instead, bigger particle size of natural calcium carbonate (calcite) presented lower compressive resistance, thus less dense residue. However, residue of calcite composite presented higher force and energy required to break down their residues compared to wollastonite and calcium hydroxide composites. The decrease in force, which correlates with a decrease in energy and sensor penetration (\%), means that residue of calcite composite was more cohesive and denser than residue of wollastonite and calcium hydroxide composite.

The appearance of residues after the compression tests is presented in Fig. 13. All residues of calcium-based filler and mica formed small fragments which maintained their integrity. ATH, boehmite, and alumina residues were literally squashed down to form ashes-like bits. Such final state can be correlated with the form of the compression curve quite easily: upstanding residue materials such as those obtained from calcium-based materials broke suddenly and went down to the origin rapidly (Fig. 9, except for calcium hydroxide). Conversely, crumbly materials sustain a given force even at high compression depth (see example of ATH, Fig. 10). Alumina compression curve is the only exception of compression/state of the broken residue correlation: indeed, these materials were far too crumbly to be carefully characterised by compression.

\section{Discussion}

All data gained in the results part are summarised in Tables 1 and 2 . In order to determine the cohesion of all residues obtained here by pyrolysis, two main parameters are considered (volume variation and residue behaviours under compression) and compared with external parameters (volatile release, new crystal and/or char formation and filler/polymer interaction).

\subsection{Effect of volatile release to volume variation}

Silicone composites containing water-releasing fillers presented almost identical residue microstructures, with high porosity and crater-like morphology inside, and amorphous (smooth) and cracked surface. These porosities and cracks were induced by water and volatile products released from the filler and matrix degradation, respectively. All of these also resulted in volume expansion, proportional to the content of water released, principally. Lower volume expansion of boehmite based composition compared to ATH one was observed because boehmite degradation released only $18 \mathrm{wt} \%$ of water against $35 \mathrm{wt} \%$ for ATH. Also, the temperature of water release is primordial: boehmite

Table 2

Compression resistance's behaviour of Ca and Al-based residues.

\begin{tabular}{|c|c|c|c|c|c|c|c|}
\hline \multirow[t]{2}{*}{ Filler } & \multicolumn{3}{|l|}{ Surface } & \multicolumn{4}{|l|}{ Bulk residue } \\
\hline & Force $(\mathrm{N})^{\mathrm{a}}$ & Compression depths $(\mathrm{mm})^{\mathrm{a}}$ & Slope $(\mathrm{N} / \mathrm{mm})^{\mathrm{a}}$ & Maximum force $(\mathrm{N})$ & Compression depths $(\mathrm{mm})^{\mathrm{a}}$ & Sensor Penetration $(\%)^{\mathrm{c}}$ & Energy $\left(10^{-3} \mathrm{~J}\right)^{\mathrm{b}}$ \\
\hline PCC & $27.36 \pm 3.55$ & $0.10 \pm 0.02$ & $0.470 \pm 0.178$ & $90.07 \pm 15.07$ & $0.91 \pm 0.23$ & 50.4 & $33.1 \pm 7.1$ \\
\hline Calcite & $2.78 \pm 0.38$ & $0^{\mathrm{d}}$ & $0.103 \pm 0.012$ & $24.71 \pm 2.95$ & $0.71 \pm 0.05$ & 35.7 & $10.93 \pm 1.66$ \\
\hline Wollastonite & $3.91 \pm 0.80$ & $0.17 \pm 0.04$ & $0.027 \pm 0.003$ & $11.97 \pm 1.05$ & $0.85 \pm 0.11$ & 24.1 & $4.09 \pm 0.60$ \\
\hline Calcium Hydroxide & $3.99 \pm 0.50$ & $0.14 \pm 0.02$ & $0.092 \pm 0.024$ & $7.83 \pm 1.32$ & $0.57 \pm 0.05$ & 13.7 & $2.41 \pm 0.59$ \\
\hline ATH & $0.74 \pm 0.18$ & $0.21 \pm 0.04$ & $0.007 \pm 0.003$ & $1.21 \pm 0.51$ & $1.06 \pm 0.39$ & 17.4 & $0.86 \pm 0.51$ \\
\hline Boehmite & $0.43 \pm 0.15$ & $0.20 \pm 0.06$ & $0.007 \pm 0.002$ & $2.55 \pm 0.41$ & $0.80 \pm 0.17$ & 16.8 & $0.89 \pm 0.26$ \\
\hline Alumina & $2.04 \pm 0.54$ & $0.27 \pm 0.05$ & $0.019 \pm 0.008$ & $2.87 \pm 0.38$ & $0.37 \pm 0.06$ & 6.10 & $0.70 \pm 0.18$ \\
\hline Mica & $1.81 \pm 0.34$ & $0.27 \pm 0.07$ & $0.021 \pm 0.006$ & $3.01 \pm 0.55$ & $0.75 \pm 0.44$ & 16.6 & $1.18 \pm 0.72$ \\
\hline Matrix 25\% Silica & $1.91 \pm 0.21$ & $0.09 \pm 0.03$ & $0.055 \pm 0.020$ & $2.64 \pm 0.39$ & $0.29 \pm 0.06$ & 8.10 & $0.45 \pm 0.16$ \\
\hline
\end{tabular}

\footnotetext{
a Collected for the first time residue is broken under compression.

b At the maximum force.

c Calculated by considering the volume variation of residue.

d The outer layer of calcite residue did not generate a specific compressive resistance (see Fig. 9).
} 

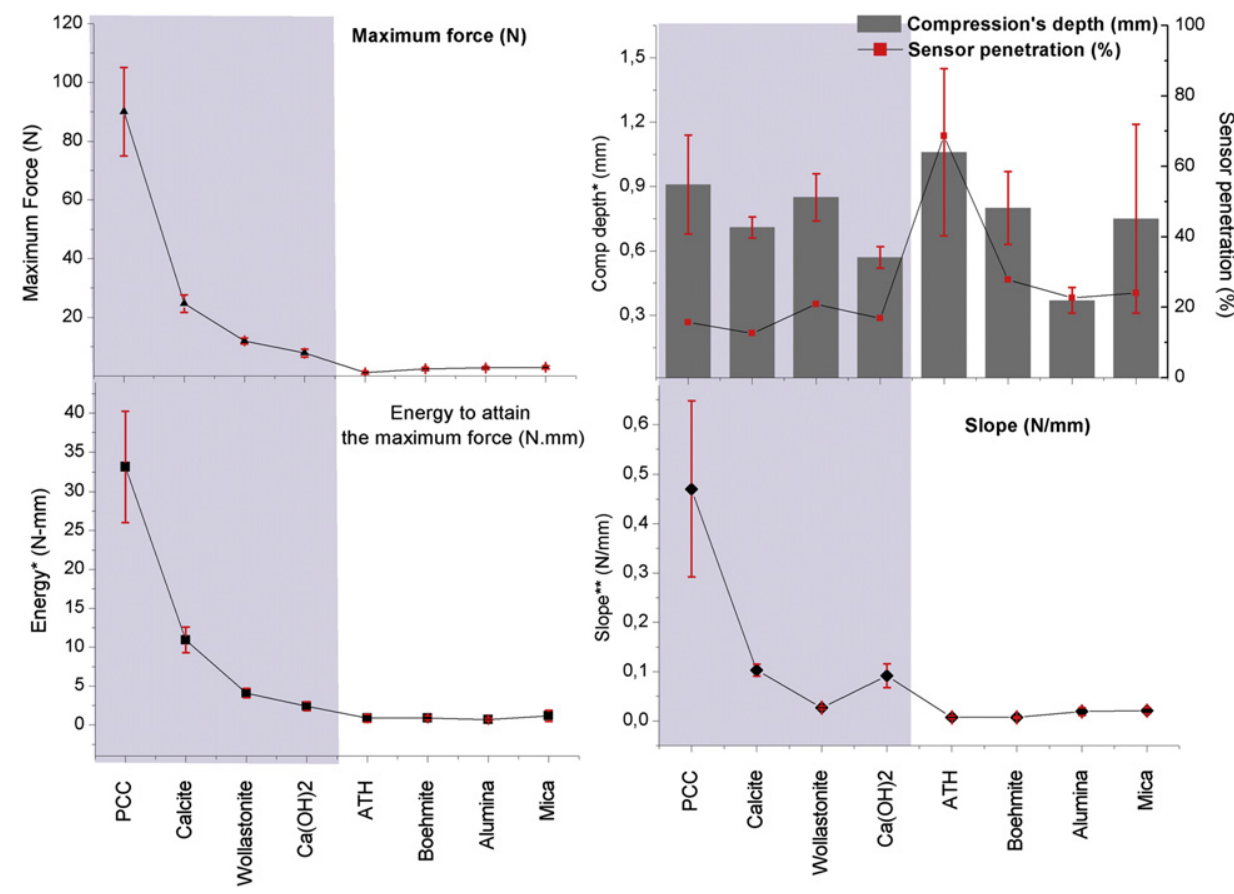

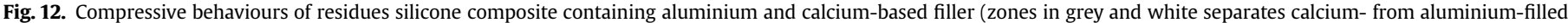
silicone composite residues).

releases water at about the same temperature as silicone degradation (from $380{ }^{\circ} \mathrm{C}$ to $550{ }^{\circ} \mathrm{C}$ ), so that it has a lower catalytic effect on silicone degradation than $\mathrm{ATH}$, which initial degradation temperature is rather low (from $220^{\circ} \mathrm{C}$ to $380^{\circ} \mathrm{C}$ ) [6]. High volume expansion of alumina fillers can be explained by the very high surface area developed by the nanoparticles, so that more hydroxyl groups were able to promote silicone degradation. Unless other fillers, low volume expansion of mica contributed to filler good cohesion to matrix surface. In addition, as reported previously by Mansouri et al. [5], mica could produce a eutectic liquid at high temperature to facilitate the formation of a strong ceramic layer. This eutectic liquid of mica can form at the interface on heating around $900{ }^{\circ} \mathrm{C}$ to act as a bridge between the silicon dioxide particles and the mica particles, giving a coherent structure at the firing temperature. Lamellar shape and big particle size of mica bound well to the matrix to form an effective protective layer and limit the volume variation.

Silicone composites containing $\mathrm{CO}_{2}$-releasing fillers were shown to induce almost no porosity inside the residue, and on the contrary led to a severe shrinkage. They even showed higher volume shrinkage than for wollastonite. $\mathrm{CO}_{2}$ release during sample pyrolysis did not result in matrix degradation, thus confirming that this gas is inert towards silicones. In addition to that, co-crystallisation occurring at high temperature surely helped to densify the residue and to reduce the porosity, resulting in the shrinkage of the residues. The shrinkage volume of residue observed for wollastonite composite is attributed only to the loss of cyclic siloxanes during matrix degradation, since wollastonite is inert towards silicone.

Calcium hydroxide showed a behaviour in-between the two former cases. Whereas volume expansion would be expected since
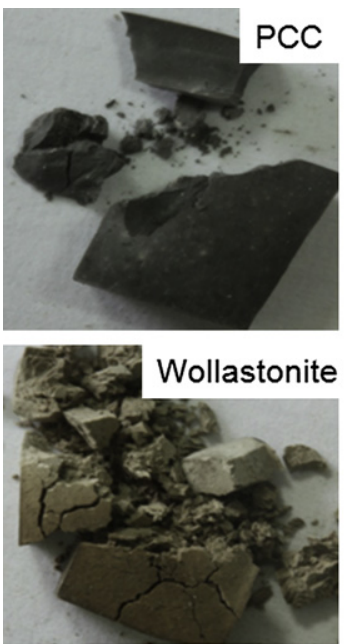
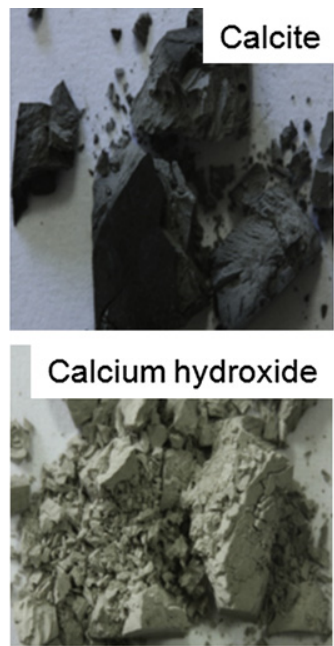
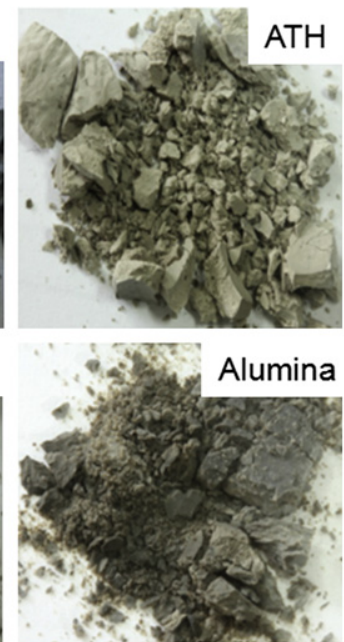
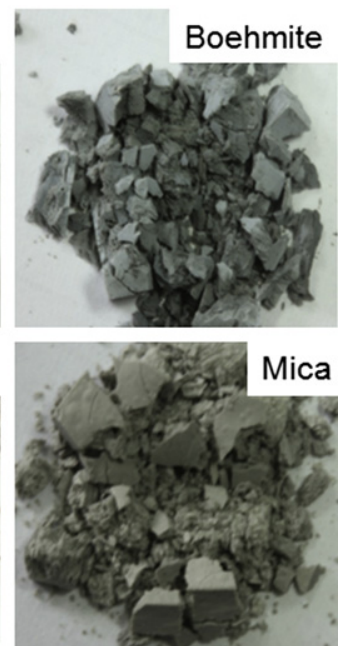

Fig. 13. Residues appearance after compression tests. 


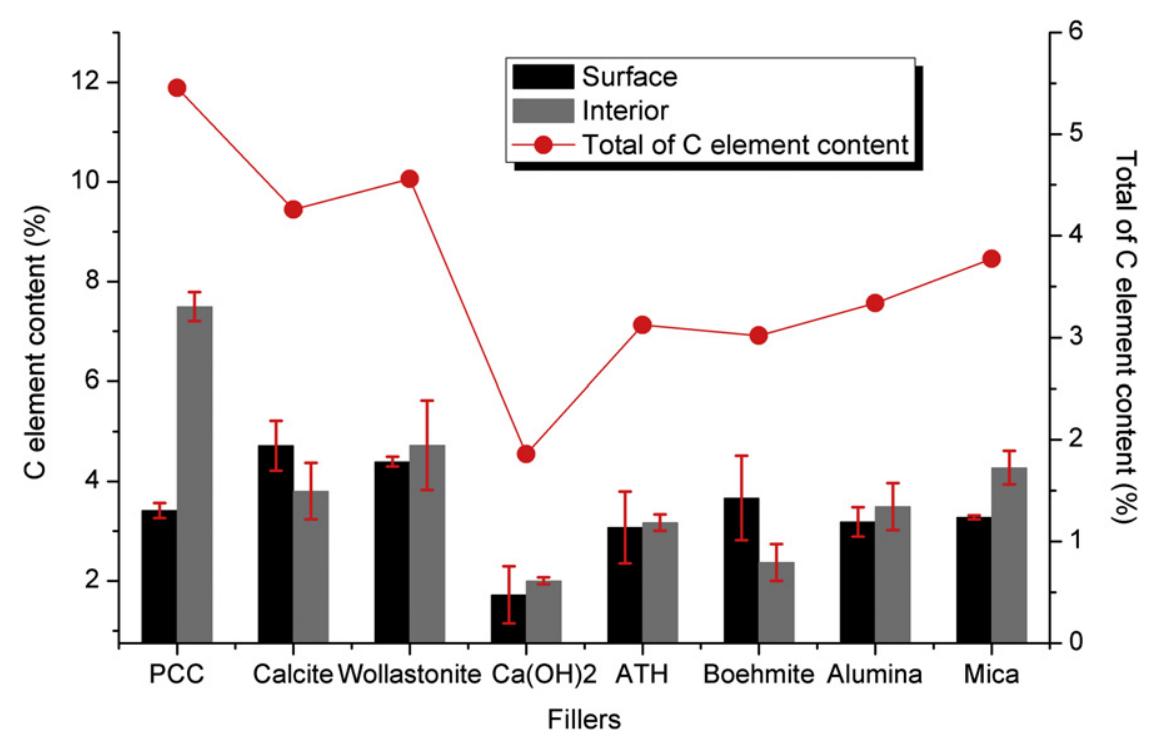

Fig. 14. Carbon element content in the residues of silicone composite. Total $C$ element content is the addition of $C$ element content on surface and interior of residue.

water release shall promote matrix degradation, co-crystallisation involving calcium oxide should also limit its volume expansion, as for the other Ca-based composites. It seems that water release had a low catalytic effect on matrix degradation, since calcium hydroxide degradation temperature occurs at the same time than matrix degradation (between $400{ }^{\circ} \mathrm{C}$ and $600{ }^{\circ} \mathrm{C}$ ).

\subsection{Effect of co-crystallisation to compression behaviour}

The occurrence of co-crystallisation in residues was believed to be at the origin of their compression resistance. Co-crystallisation between filler and matrix at high temperature modifies the microstructure of residue, providing denser residue and improving its structural strength. The unsatisfactory compression behaviour of residue of silicone composite containing aluminium-based filler is certainly due to the absence of co-crystallisation at high temperature.

PCC and calcite presented better compression resistance because they have a very compact residue as the result of structure rearrangement by co-crystallisation. Compared to calcite, the nanosized of calcium carbonate in PCC surely presents higher surface activity towards silica in co-crystallisation (for a complete characterisation of particle sizes and structures, see [6]). Thanks to cocrystallisation, calcium hydroxide composite showed better compressive resistance than all-water releasing fillers even though it presented high interior porosity due to water-release. Unlike in residue of aluminium-based fillers, these interior porosities were surrounded by a continuous ceramic layer (glassy layer) as seen in ESEM images (Fig. 5) because volatiles release (water or cyclic siloxanes) was followed by a successive co-crystallisation at high temperature, which densifies the residue. Unfortunately, the interior porosity makes the residue of calcium hydroxide composite more fragile than wollastonite composite. Residue of silicone composite containing wollastonite also showed good cohesion, even though wollastonite filler did not co-crystallise with silicone matrix nor did it bind to the matrix.

\subsection{Char formation to residue content}

Shephard [8] has reported that increasing contents of wollastonite into silicone resulted in a tough resinous char, i.e. a partly carbonaceous residue, with few surface cracks and high surface integrity. This char formation was confirmed here by the high total carbon element content measured for wollastonite residue, as well as in the interior of the mica residue (Fig. 14). Lamellar shape of mica or wollastonite favours a mass barrier effect which limits the volatile release. Also, the occurrence of micro-bridge formation between wollastonite particle and matrix residue should increase ash strength.

Nano-fillers of PCC and alumina composites also presented high carbon element content in their residues. The presence of nanoparticles in polymer induces tortuosity in volatiles' release pathway [9-11]. Hence, carbon-rich residue of PCC presents better compressive resistance of PCC than calcite; similarly, the carbonrich char formation in alumina residue results in slightly higher compressive resistance than ATH or boehmite (Table 2). Nevertheless, this char formation is not enough to provide high compressive resistance of residue. Submicronic boehmite showed no improvement in charring residue; its acicular particle shape seems not to be able to increase either the tortuosity in composite or mass barrier on surface.

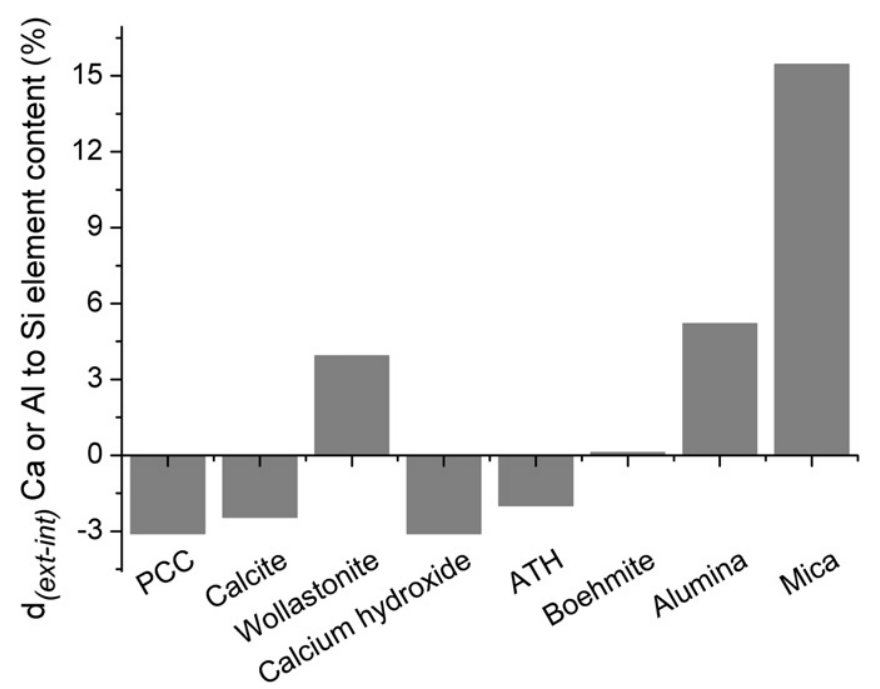

Fig. 15. Differences between $\mathrm{Ca}$ or $\mathrm{Al}$ to Si element content on surface and interior of silicone composites after pyrolysis. 
We also calculated the difference between Ca or Al to Si element content in surface and interior of residue, express as $d_{\text {(ext-int) }}$ in Equation (3).

$d_{(\text {ext-int })}(\%)=\frac{(\% \text { Element })_{\text {Surface }}-(\% \text { Element })_{\text {Interior }}}{(\% \text { Element })_{\text {Surface }}+(\% \text { Element })_{\text {Interior }}} \times 100$

where \% Element refers to $\mathrm{Al}$ or Ca element content to Si element content on surface or interior of residue. The positive values of

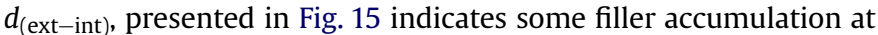
the surface of the material and/or polymer ablation. Mica, wollastonite, and alumina fillers showed higher Al or Ca element content on surface of residue. PCC filler was on the opposite rather located inside the residue, where charring mostly occurred, as seen in Fig. 14.

Large size and high filler density of wollastonite and mica particles [6] do not speak in favour of their migration to the surface. Since both of them sustain the tested temperature, and do not transform at high temperature, the presence of excess mica or wollastonite on residue surface can thus only be attributed to polymer ablation during burning, leaving filler poles on the burned material. On the opposite, the presence of alumina particles on surface of residue could likely be ascribed to filler migration to surface, since alumina nanoparticles exhibit very small filler density [6].

\section{Conclusions}

The state of the residues of calcium and aluminium-based composites after pyrolysis has been observed by different techniques of microscopy (optical and scanning electronic microscopy), elemental analysis (XRD, EDX) and physical characterisation (volume expansion, compression curves). The filler nature and the co-crystallisation and/or charring at high temperature are the two key parameters to achieve a cohesive residue. Filler nature strongly influences the residue's morphology by the formation of interior porosity, indirectly also varying its volume. The presence of water from filler degradation weakens the residues, because of interior porosity, and expanses their volume. Besides, co-crystallisation is believed to control the residues' compression resistance. As a matter of fact, the presence of cracks is not important, since the surface effect on the compressive resistance of bulk residue is not significant. All residues of composites containing aluminium-based fillers are fragile without any cohesion residue, due to the absence of filler-matrix interaction at high temperature (co-crystallisation). On the group of residues containing calcium-based fillers, residue of PCC presented the strongest ceramified residue. Residue of PCC composite is tough and very dense, and as a consequence, it requires more energy to break down under compression compared to calcite, wollastonite and calcium hydroxide. For this particular filler, co-crystallisation and char formation in the interior of residue explain such interesting result. Mica and wollastonite also showed slightly better cohesion residue thanks to char formation.

The above conclusions can be challenged in regards of the NFC 32070 CR1 standard test. In our simplified pyrolysis test, we did not check the influence of the presence of the copper wire and of the mechanical shocks. Those two process variations can however be discussed based on volume variation analysis and compressive test, respectively. The copper wire expands with temperature: if the material shrinks during pyrolysis, cracks will likely form and weaken the cable. On the other hand, volume expansion would inherently degrade the cable homogeneity, not considering the copper wire. One should thus seek a material filled with additives so that volume variation would be nil. Concerning the shock resistance, the compression tests predicted that a ceramic material be used to pass such drastic specification. A combination of fillers should provide a material both with no volume variation and sufficient ceramization behaviour. The use of a filler able to cocrystallise with silica, and to degrade without releasing water is thus highly recommended to obtain composites with good cohesion residue. Alternatively, adding to the formulation a filler that forms a liquid phase at high temperature (for example glass frits) could be an advantage, in order to strengthen the residue through micro-bridge formations between mica or wollastonite particles with silica. Using a calcium carbonate filler alone (either PCC or calcite) provokes a very high residual shrinkage, whereas boehmite or mica does not generate a cohesive residue. Optimised combination of PCC or calcite with aluminium-based filler such as boehmite or mica could be of prime interest to limit the volume variation inappropriate for electrical cable applications. Real industrial tests are currently performed on optimised formulations arising from this comprehensive study.

\section{Acknowledgements}

We are most grateful to Bluestar Silicones for providing all the silicone raw materials that were necessary to carry out this study. We also thank Solvay, Nyco Minerals and Nabaltec for donating PCC, Wollastonite and Boehmite, respectively.

\section{Appendix. Supplementary data}

Supplementary data associated with this article can be found in the online version, at doi:10.1016/j.polymdegradstab.2011.05.019.

\section{References}

[1] Kaufmann W, Prager FH, Schiffer HW. Electrical engineering. In: Troitzsch J, editor. International plastics flammability handbook. 2nd ed. Munich: Hanser; 1990. p. 344-78.

[2] British Standard BS EN 50200. Method of test for resistance to fire of unprotected small cables for use in emergency circuits. British Standard Institution; 2006.

[3] Laoutid F, Ferry L, Leroy E, Lopez Cuesta JM. Intumescent mineral fire retardant systems in ethylene-vinyl acetate copolymer: effect of silica particles on char cohesion. Polym Deg Stab 2006;91:2140-5.

[4] Beyer G. Flame retardancy of nanocomposites based on organoclays and carbon nanotubes with aluminium trihydrate. Polym Adv Technol 2006;17 218-25.

[5] Mansouri J, Burford RP, Cheng YB, Hanu L. Formation of strong ceramified ash from silicone-based compositions. J Mater Sci 2005;40:5741-9.

[6] Hamdani S, Longuet C, Lopez-Cuesta JM, Ganachaud F. Calcium and aluminum-based fillers as flame-retardant additives in silicone matrices. I. Blends preparation and thermal properties. Polym Deg Stab 2010;95:1911-9.

[7] Mansouri J, Burford RP, Cheng YB. Pyrolysis behaviour of silicone-based ceramifying composites. Mater Sci Eng A 2006;425:7-14.

[8] Shephard KL. Flame resistant silicone rubber wire and cable coating composition. May 2001. United States Patent 6239378.

[9] Leszczyńska A, Njuguna J, Pielichowski K, Banerjee JR. Polymer/montmorillonite nanocomposites with improved thermal properties. Part I: Factors influencing thermal stability and mechanisms of thermal stability improvement. Thermochim Acta 2007;453:75-96.

[10] Burnside SD, Giannelis EP. Synthesis and properties of new poly(dimethylsiloxane) nanocomposites. Chem Mater 1995;7(9):1597-600.

[11] Burnside SD, Giannelis EP. Nanostructure and properties of polysiloxanelayered silicate nanocomposites. Polym Sci Part B Polym Phys 2000;38: 1595-604. 